\title{
Trade openness and policy tools: a vulnerability approach for the Italian regions
}

\author{
A. Federici \\ ENEA - Italian National Agency for New Technologies, \\ Energy and the Environment, Italy
}

\begin{abstract}
This paper analyses the phenomenon of macro vulnerability linked to trade openness, underlining the role of policy tools in reducing exposure to external shocks. Vulnerability as a method of analysis does not override traditional approaches, offering instead a new lens to examine the dynamics of development. Vulnerability can be defined as the "continuous forward looking state of expected outcomes": while well being and poverty are ex post outcomes, vulnerability is an ex ante condition that could potentially lead to a negative outcome. The main result of the empirical analysis is that the regions of the South of Italy have experienced a worsening of their macroeconomic well being. This has to be related to the limited ability to cope with higher degrees of uncertainty as well as poor use of adequate policy tools that are able to mitigate the repercussions of trade shocks on the domestic economy. This output implies the need to adopt new, specific and forward looking macroeconomic policies able both to support the process of trade liberalization and to limit risk exposure and enhance the response capabilities of the population.
\end{abstract}

Keywords: vulnerability, volatility, international trade, regional development, Italian regions.

\section{Introduction}

The aim of this paper is to detect empirically the phenomenon of macrovulnerability linked to trade openness, underlining the role of policy tools in reducing exposure to external shocks: to this aim an ad hoc methodology will be developed to offer a preliminary answer to this issue. 
Mainstream international economics based on the Heckscher-Ohlin theory assert that international trade produces benefits for all participants. Notwithstanding, over time a huge number of studies explored additional issues on the effects of trade openness on partner countries, presenting a substantial empirical evidence about the impact of trade liberalization on poverty, (Timmer [1], Delgado et al. [2]), the relationship between trade integration and economic growth, (Edwards [3], Frankel and Romer [4], Dollar and Kraay [5]), and the role of policies and institutions (Krueger [6], Ades and Di Tella [7,8], Lall and Pietrobelli [9]). More recently, a growing attention has been devoted to the issue of trade liberalization and vulnerability.

Vulnerability as a method of analysis does not override traditional approaches, offering instead a new lens to examine the dynamics of development. It can be defined as the "continuous forward looking state of expected outcomes" (Alwang et al. [10]) which are in themselves determined by the characteristics of the unit of analysis, the correlation and severity of shocks, and also by the risk management instruments applied (Heitzmann et al. [11]). Risks, in fact, are only one side of the coin: while risks are exogenous, vulnerability is endogenous as it is the result of strategies employed by individuals and/or communities to face risks. It is important to underline that while well being and poverty are ex post outcomes, vulnerability is an ex ante condition which could potentially lead to a negative outcome. Consequently, what really matters when assessing vulnerability is not the current values of the phenomena, but the ability to understand their future dynamics and intervene when needed.

There are currently a number of different approaches of analysis on vulnerability (for an overview see Ligon and Schechter [12]: they adopt primarily a micro approach and focus on households).

\section{Towards a macro approach of vulnerability}

This paper adopts a macro lens and a slightly different approach. The choice to focus on aggregate variables and not on households data is due, first of all, to the consciousness that the economic process of globalization is leading to a different situation where endogenous, micro and natural shocks are becoming less important than man made external macro shocks. Especially in the last decade the incidence of macro shocks at the international level has been quantitatively very relevant.

The second reason that calls for a macro approach is related to policy. Recent events proved a lack of ex ante international macroeconomic policies capable of properly recognizing and coping with the systemic nature of macroeconomic crises and their actual effects. As a result, policies need to be redesigned and redirected to address such issues (Holzmann and Jorgensen [13], Holzmann [14]).

Finally, the adoption of a macro approach could be useful to raise a critique to the influential current macro literature on trade and poverty, which argues that trade is good for growth (Dollar and Kraay [15]). It will help also to underline 
the fundamental role of the regional characteristics and cross regions comparison in determining the ability of a region to benefit from a full integration within a more open international economic environment.

The most important achievements on the role of trade shocks and covariate risks have been given by the literature on macro volatility: for this reason this paper establishes a link between trade vulnerability analyses and macro volatility studies (for a comprehensive survey of the literature on volatility and an overview of the methodological framework see Montalbano et al. [16]).

\section{A suggested model of macroeconomic vulnerability to trade}

Starting from traditional micro vulnerability literature, in order to extend vulnerability analysis to a higher level of aggregation, a panel of regions is chosen rather than a panel of households and the proposed measurement of welfare is based on the average growth of annual per capita consumption expenditure.

Then a mixed approach to detect vulnerability is adopted. Firstly, recalling Ligon and Schechter [17], vulnerability of country $i$ is defined as the difference between the expected average growth of per capita consumption under the hypothesis of no shocks and the expected value of the same variable under the hypothesis of shocks. In formula:

$$
V\left(c_{i}\right)=\frac{E\left[\overline{\dot{c}}_{i}^{*}\right]-E\left[\dot{\bar{c}}_{i}\right]}{E\left[\overline{\dot{c}}_{i}\right]}
$$

hence, $\mathrm{E}\left[\overline{\dot{c}}_{i}^{*}\right]$ is a benchmark and in the case of negative shock, the proposed measure is negative. The larger the rate of change, the higher the vulnerability of the region $i$.

Moreover, according to vulnerability literature, the average growth of per capita consumption depends upon the volatility of its annual rates of change. In formula:

$$
\overline{\dot{c}}_{i}=f\left(\operatorname{vol}\left(\dot{c}_{i t}\right) ; F P_{i}\right), i=1, \ldots, n, t=1, \ldots, T
$$

where $\operatorname{vol}\left(\dot{c}_{i t}\right)$ is the standard deviation of the rates of change of per capita consumption and $F P_{i}$ denotes the fiscal policy.

Finally, according to Amin et al. [18], Glewwe and Hall [19] and the literature about the determinants of volatility, volatility of consumption expenditures is linked to trade openness, as follows:

$$
\operatorname{vol}\left(\dot{c}_{i t}\right)=g\left(\operatorname{vol}\left(\dot{x}_{i t}\right)\right), i=1 \ldots n
$$

where $\operatorname{vol}\left(\dot{x}_{i t}\right)$ is the volatility of the rates of change of the international trade openness of region $i$, adopted as instrument in eqn (2).

Practically speaking, as highlighted by eqns (2) and (3), an increased volatility of variables related to trade openness will cause an increased volatility of per capita consumption growth with effects on the consumption performances. 
According to this model, cross regional differences in the volatility of per capita consumption growth can alternatively arise from differences in the exposure of trade shocks or in the availability of coping mechanisms, producing different welfare conditions (Wolf [20]). This, in turn, according to eqn (1) widens the rate of change between the expected value of actual per capita consumption growth and its potential value (i.e. our benchmark). The wider this rate of change the more vulnerable the analysed unit.

\section{The vulnerability of Italian regions}

\subsection{Average performance and volatility}

Total volatility of per capita consumption has been decomposed into normal, extreme and crisis components (Table 1): normal volatility represents the repeated and small cyclical movements around the mean, while extreme and crisis volatility reflect the impacts of sharp fluctuations, both positive and negative in the former case, only negative in the latter one.

Table 1: Volatility decomposition and performance of per capita consumption.

\begin{tabular}{|l|c|ccc|c|c|}
\hline & \multirow{7}{*}{$\begin{array}{c}\text { Average } \\
\text { Region }\end{array}$} & \multicolumn{5}{|c|}{ Volatility } \\
\cline { 3 - 7 } performance & Crisis & Normal & Boom & Total & Extreme \\
\hline Piedmont & $1,58 \%$ & 0,010 & 0,004 & 0,005 & 0,019 & 0,015 \\
Valle D'Aosta & $1,80 \%$ & 0,011 & 0,004 & 0,008 & 0,023 & 0,019 \\
Lombardy & $1,49 \%$ & 0,014 & 0,005 & 0,000 & 0,018 & 0,014 \\
Trentino - Alto Adige & $1,42 \%$ & 0,008 & 0,004 & 0,007 & 0,019 & 0,015 \\
Veneto & $2,01 \%$ & 0,012 & 0,004 & 0,002 & 0,018 & 0,014 \\
Friuli - Venezia Giulia & $2,08 \%$ & 0,011 & 0,003 & 0,002 & 0,016 & 0,014 \\
Liguria & $1,61 \%$ & 0,011 & 0,004 & 0,002 & 0,017 & 0,013 \\
Emilia - Romagna & $2,29 \%$ & 0,011 & 0,006 & 0,000 & 0,017 & 0,011 \\
Tuscany & $1,95 \%$ & 0,010 & 0,005 & 0,000 & 0,014 & 0,010 \\
Umbria & $1,64 \%$ & 0,013 & 0,005 & 0,003 & 0,021 & 0,016 \\
Marches & $2,22 \%$ & 0,007 & 0,005 & 0,003 & 0,015 & 0,010 \\
Latium & $1,54 \%$ & 0,014 & 0,003 & 0,005 & 0,021 & 0,018 \\
Abruzzo & $1,33 \%$ & 0,013 & 0,003 & 0,003 & 0,019 & 0,016 \\
Molise & $2,01 \%$ & 0,010 & 0,005 & 0,003 & 0,018 & 0,013 \\
Campania & $1,34 \%$ & 0,012 & 0,005 & 0,004 & 0,021 & 0,016 \\
Apulia & $1,42 \%$ & 0,010 & 0,003 & 0,003 & 0,016 & 0,013 \\
Basilicata & $1,87 \%$ & 0,014 & 0,003 & 0,003 & 0,020 & 0,017 \\
Calabria & $1,71 \%$ & 0,010 & 0,004 & 0,003 & 0,017 & 0,013 \\
Sicily & $1,38 \%$ & 0,014 & 0,003 & 0,006 & 0,022 & 0,020 \\
Sardinia & $1,64 \%$ & 0,009 & 0,001 & 0,005 & 0,015 & 0,014 \\
\hline Italy & $\mathbf{1 . 7 2 \%}$ & $\mathbf{0 . 0 1 1}$ & $\mathbf{0 . 0 0 4}$ & $\mathbf{0 . 0 0 3}$ & $\mathbf{0 . 0 1 8}$ & $\mathbf{0 . 0 1 5}$ \\
\hline North-West & $1.62 \%$ & 0.011 & 0.004 & 0.004 & 0.019 & 0.015 \\
\hline North-East & $1.95 \%$ & 0.011 & 0.004 & 0.003 & 0.018 & 0.013 \\
\hline Centre & $1.84 \%$ & 0.011 & 0.004 & 0.003 & 0.018 & 0.013 \\
\hline Mezzogiorno & $1.59 \%$ & 0.012 & 0.003 & 0.004 & 0.018 & 0.015 \\
\hline & & & & & &
\end{tabular}


More specifically, crisis volatility is defined as the portion of the standard deviation of the rates of change of per capita consumption that corresponds to downward deviations below a threshold equal to the mean of the distribution of overall volatility measures (thus, it is common to all regions). Using a common threshold generates absolute (as opposed to relative, region-specific) crisis measures and facilitates cross-regions comparisons. Normal volatility is then defined as the portion of the standard deviation corresponding to deviations that fall within the thresholds (see World Bank [21] for a deeper overview).

In the period 1990-2000, the best performances for per capita consumption expenditure has been observed for North-East and Centre, Emilia Romagna and Marches in particular; on the contrary, Abruzzo and Campania show the lowest average rates of change. As shown in Table 1, Mezzogiorno and North-West present the highest values for the extreme component, but in the second case the large observed volatility is due in particular to the highly volatile behaviour of Valle d'Aosta, more liable to fluctuations as all small regions in general.

\subsection{Determinants of volatility: the role of trade openness}

Also in the case of international trade openness (defined as the sum of import and export over GDP), some of the observed fluctuations have to be considered as normal: policy tools managed by practitioners are able to effectively balance restrained rates of change. On the contrary, extreme fluctuations will have negative repercussions upon regional development. Table 2 illustrates how the volatility of the rates of change is larger for the regions of Mezzogiorno, especially in the case of its extreme component.

Table 2: $\quad$ Volatility of international trade openness rates of change.

\begin{tabular}{|l|c|c|l|c|c|}
\hline Region & Total & Extreme & Region & Total & Extreme \\
\hline Piedmont & 0,081 & 0,028 & Molise & 0,146 & 0,116 \\
Valle D'Aosta & 0,237 & 0,233 & Campania & 0,061 & 0,000 \\
Lombardy & 0,069 & 0,000 & Apulia & 0,093 & 0,039 \\
Trentino - Alto Adige & 0,087 & 0,062 & Basilicata & 0,273 & 0,273 \\
Veneto & 0,071 & 0,000 & Calabria & 0,088 & 0,036 \\
Friuli - Venezia Giulia & 0,099 & 0,028 & Sicily & 0,197 & 0,177 \\
Liguria & 0,120 & 0,094 & Sardinia & 0,222 & 0,215 \\
Emilia - Romagna & 0,066 & 0,000 & Macro Areas & Total & Extreme \\
\cline { 4 - 7 } Tuscany & 0,090 & 0,021 & North-West & 0,127 & 0,089 \\
Umbria & 0,123 & 0,094 & North-East & 0,081 & 0,022 \\
Marches & 0,101 & 0,037 & Centre & 0,099 & 0,045 \\
Latium & 0,080 & 0,027 & Mezzogiorno & 0,157 & 0,128 \\
\cline { 4 - 4 } & 0,177 & 0,163 & Italy & $\mathbf{0 , 1 2 4}$ & $\mathbf{0 , 0 8 2}$ \\
\hline
\end{tabular}

To check whether consumption volatility is associated with trade shocks, consistently with eqn (3) of the proposed model, the volatility of the rates of change of per capita consumption is regressed on the extreme volatility of the rates of change of international trade openness.

The fit of the regression is good, and all coefficients are robust, significant and bear the expected signs: Table 3 proves how the international trade openness 
volatility amplifies the per capita consumption one. A distinction among the components of volatility is necessary: the effect on total volatility is positive but it is the result of a reduction of structural fluctuations balanced more than proportionally by the improvement of extreme ones, crisis volatility in particular.

Table 3: Incidence of extreme international trade openness volatility.

\begin{tabular}{|l|cccc|}
\hline Variable $\backslash M o d e l$ & Total & Normal & Extreme & Crisis \\
\hline Constant & 0.0169 & 0.0045 & 0.0132 & 0.0104 \\
p-value & 0.000 & 0.000 & 0.000 & 0.000 \\
Trade openness extreme volatility & 0.0182 & -0.0072 & 0.0167 & 0.0098 \\
p-value & 0.006 & 0.015 & 0.016 & 0.092 \\
\hline $\mathbf{R}^{2}$ Adjusted & 0.344 & 0.248 & 0.241 & 0.115 \\
\hline
\end{tabular}

\subsection{The relationship between performance and volatility}

According to the proposed model, the paper tests whether higher levels of the volatility of the rates of change of per capita consumption really worsen the macroeconomic performance of regions in terms of average growth during the sampled period. Of course, determinants of volatility analysed in the previous section will be considered as instruments within an instrumental variable framework.

As shown by Table 4, fluctuations of rates of change negatively affect the average performance of the single Italian regions (model 1); however, the incidence of normal volatility (model 2 ) is not so much as both extreme (model 3 ) and, in particular, crisis component effect (model 4).

Consistently with the expectations, the estimation concerning normal volatility assesses a positive relationship between the two variables: according to the literature there is a structural level of volatility, which doesn't affect growth and is considered as a positive indicator of economic activity.

The model stresses the importance of the countercyclical behaviour in the policy tools management (that is a negative correlation between the rate of change of the public regional expenditure and the rate of change of per capita consumption), able to partly offset the negative effects of volatility.

Table 4: $\quad$ Incidence of volatility on average performance.

\begin{tabular}{|l|cccc|}
\hline \multicolumn{1}{|c|}{ Model } & 1 & 2 & 3 & 4 \\
Variable & & & & \\
\hline Constant & 0.0171 & 0.0171 & 0.0171 & 0.0174 \\
p-value & 0.000 & 0.000 & 0.000 & 0.000 \\
Total volatility & -0.6599 & & & \\
p-value & 0.018 & & & \\
Normal volatility & & 1.3900 & & \\
p-value & & 0.017 & & \\
Extreme volatility & & & -0.6851 & \\
p-value & & & 0.004 & \\
Crisis volatility & & & & -0.7135 \\
p-value & & & & 0.080 \\
Procyclicality & -0.0046 & -0.0054 & -0.0044 & -0.0058 \\
p-value & 0.009 & 0.002 & 0.005 & 0.004 \\
\hline R Adjusted & 0.493 & 0.477 & 0.559 & 0.433 \\
\hline \multicolumn{2}{|l}{} \\
\hline
\end{tabular}


In accordance with the proposed models, the expected average rate of change with zero volatility (that is a measure of the potential average growth of per capita consumption) is thus estimated and compared with the actual levels of expected average rate of change in presence of volatility.

Table 5: Impact of consumption volatility on the annual average performance.

\begin{tabular}{|l|c|c|c|l|c|c|c|}
\hline Region & Total & Extr. & Crisis & Region & Total & Extr. & Crisis \\
\hline Piedmont & $-1.24 \%$ & $-1.01 \%$ & $-0.71 \%$ & Molise & $-1.17 \%$ & $-0.89 \%$ & $-0.69 \%$ \\
Valle D'Aosta & $-1.50 \%$ & $-1.31 \%$ & $-0.77 \%$ & Campania & $-1.36 \%$ & $-1.10 \%$ & $-0.85 \%$ \\
Lombardy & $-1.22 \%$ & $-0.94 \%$ & $-0.98 \%$ & Apulia & $-1.04 \%$ & $-0.89 \%$ & $-0.74 \%$ \\
Trentino - Alto Adige & $-1.27 \%$ & $-1.02 \%$ & $-0.58 \%$ & Basilicata & $-1.34 \%$ & $-1.19 \%$ & $-1.03 \%$ \\
Veneto & $-1.22 \%$ & $-0.99 \%$ & $-0.87 \%$ & Calabria & $-1.11 \%$ & $-0.90 \%$ & $-0.69 \%$ \\
Friuli - Venezia Giulia & $-1.07 \%$ & $-0.94 \%$ & $-0.82 \%$ & Sicily & $-1.46 \%$ & $-1.34 \%$ & $-0.98 \%$ \\
Liguria & $-1.13 \%$ & $-0.87 \%$ & $-0.76 \%$ & Sardinia & $-1.02 \%$ & $-0.98 \%$ & $-0.66 \%$ \\
Emilia - Romagna & $-1.12 \%$ & $-0.74 \%$ & $-0.77 \%$ & Macro Areas & Total & Extr. & Crisis \\
\cline { 2 - 7 } Tuscany & $-0.95 \%$ & $-0.66 \%$ & $-0.69 \%$ & North-West & $-1.27 \%$ & $-1.03 \%$ & $-0.80 \%$ \\
Umbria & $-1.40 \%$ & $-1.08 \%$ & $-0.93 \%$ & North-East & $-1.17 \%$ & $-0.92 \%$ & $-0.76 \%$ \\
Marches & $-0.97 \%$ & $-0.68 \%$ & $-0.50 \%$ & Centre & $-1.18 \%$ & $-0.92 \%$ & $-0.77 \%$ \\
Latium & $-1.39 \%$ & $-1.26 \%$ & $-0.97 \%$ & Mezzogiorno & $-1.21 \%$ & $-1.05 \%$ & $-0.82 \%$ \\
Abruzzo & $-1.23 \%$ & $-1.08 \%$ & $-0.95 \%$ & Italy & $-1.21 \%$ & $-0.99 \%$ & $-0.80 \%$ \\
\hline
\end{tabular}

The worst performances are for the regions of the South: if they had been able to reduce their degree of per capita consumption volatility, they would have achieved higher level of welfare during the $90 \mathrm{~s}$. This is precisely what this paper is aiming to demonstrate.

\subsection{The macro economic vulnerability of Italian regions}

Since vulnerability is, by definition, a forward looking approach, the measurement of vulnerability to trade openness calls for statements about the expected value of macroeconomic performance. To reach this task, for each region the actual probability to suffer a reduction in its average growth of per capita consumption due to a trade shock is calculated, that is the probability of a larger international trade openness volatility.

Because of the lack of a time series of enough length, future volatility has been set equal to past volatility observed in the analysed sample (World Bank [21]): independently from the way volatility is modelled, the proposed methodology wants to focus its attention on the forward looking perspective. Indeed, vulnerability approach has to take into account not only the negative effect on welfare due to a shock, but also its relative degree of risk.

For the volatility of the rates of change of the international trade openness, a shock equal to the average volatility observed in the overall sample has been considered in this conceptual experiment. Under the hypothesis of a normal distribution of the rates of change of trade openness, we tested the following hypothesis: $\mathrm{H}_{0}: \mathrm{s}^{2} \leq \sigma^{2}$ against $\mathrm{H}_{1}: \mathrm{s}^{2}>\sigma^{2}$. Under the null hypothesis, the statistic $\left[\mathrm{s}^{2}(n-1) / \sigma^{2}\right]$ shows a $\chi_{n-1}^{2}$ distribution, where $n$ is the number of years considered 
in the forecast, $s^{2}$ is the extreme volatility observed over sample and $\sigma^{2}$ is the assumed higher extreme volatility.

The final effects on the average performance are extremely homogenous within Italian regions; conversely, the probability of the occurrence of the given shock show sharp differences among geographical areas. With the only exception of Valle d'Aosta, only the regions of Mezzogiorno exhibit significant values for the probability of the occurrence of a future shock.

Trade off between risk and final effect is evident: for example, though the impact on the performance of per capita consumption of Basilicata is half of the one assessed for Campania, the probability of shock is equal to $36,6 \%$ in the former case and quite zero in the latter one. The proposed vulnerability index (columns 3 and 5) has been set equal to the absolute value of the product between the probability of shock and its assessed effect: higher the value of the index, larger the degree of vulnerability.

As shown in Table 6 Basilicata is the most vulnerable region, followed by Valle d'Aosta, Sardinia, Sicily, Abruzzo and Molise; on the contrary, the least vulnerable Italian regions are Lombardy, Piedmont, Veneto and Emilia Romagna, which are also the most integrated in the international markets. Consistently with literature, a higher level of international trade openness allows them to effectively diversify the risk.

Table 6: $\quad$ Vulnerability of Italian regions.

\begin{tabular}{|l|c|c|c|}
\hline Region & Probability of shock & $\begin{array}{c}\text { Effect on per capita } \\
\text { consumption }\end{array}$ & $\begin{array}{c}\text { Vulnerability of per } \\
\text { capita consumption }\end{array}$ \\
\hline Piedmont & $1.0 \%$ & $-0.10 \%$ & 0.101 \\
Valle D'Aosta & $31.8 \%$ & $-0.06 \%$ & 1.910 \\
Lombardy & $0.4 \%$ & $-0.11 \%$ & 0.038 \\
Trentino - Alto Adige & $1.5 \%$ & $-0.10 \%$ & 0.146 \\
Veneto & $0.4 \%$ & $-0.11 \%$ & 0.047 \\
Friuli - Venezia & $2.9 \%$ & $-0.09 \%$ & 0.269 \\
Giulia & $6.5 \%$ & $-0.08 \%$ & 0.549 \\
Liguria & $0.3 \%$ & $-0.11 \%$ & 0.030 \\
Emilia - Romagna & $1.8 \%$ & $-0.10 \%$ & 0.172 \\
Tuscany & $7.3 \%$ & $-0.08 \%$ & 0.607 \\
Umbria & $3.2 \%$ & $-0.09 \%$ & 0.293 \\
Marches & $0.9 \%$ & $-0.10 \%$ & 0.092 \\
Latium & $20.2 \%$ & $-0.07 \%$ & 1.386 \\
Abruzzo & $12.7 \%$ & $-0.08 \%$ & 0.963 \\
Molise & $0.2 \%$ & $-0.11 \%$ & 0.018 \\
Campania & $2.1 \%$ & $-0.09 \%$ & 0.204 \\
Apulia & $36.6 \%$ & $-0.06 \%$ & 2.089 \\
Basilicata & $1.5 \%$ & $-0.10 \%$ & 0.150 \\
Calabria & $24.6 \%$ & $-0.07 \%$ & 1.604 \\
Sicily & $29.3 \%$ & $-0.06 \%$ & 1.810 \\
Sardinia & & & \\
\hline
\end{tabular}

As already highlighted in the methodological section, the proposed vulnerability measure is a conceptual experiment through which, ceteris paribus, different scenarios are compared each other: the vulnerability index is a suitable early warning tool able to asses the likely effects of supposed shocks. 


\section{Conclusions}

This paper offers a substantive contribution to the debate on the role of international trade on regional development. More specifically, it tries to fill a missing link in the theory between trade shocks, volatility, and macroeconomic performance; besides, it presents a methodology to study the relationship between macro performance and trade shocks (distinguishing between normal and extreme volatility) and explores, both conceptually and empirically, the case of Italian regions. Also a general framework for the construction of a comprehensive welfare index is provided in the methodological section.

The main result of the analysis is that, in spite of the apparent association between trade openness and good macroeconomic performance, regions of Mezzogiorno have experienced a worsening of their macroeconomic well being. Moreover, the extreme volatility of trade openness turns to have remarkable negative effects on macroeconomic performances. This has to be related to the limited ability of the more fragile economic and institutional contexts of the southern regions to cope with higher degree of uncertainty as well as a poor use of adequate policy tools able to mitigate the repercussions of trade shocks on the domestic economy.

This output spurs some general and relevant policy implications. First of all, policymakers need to act in order to limit the impact of trade shocks on the volatility of their macroeconomic framework, as this is likely to worsen their macroeconomic welfare, in particular as regards its extreme and crisis components. It implies the need to adopt new, specific and forward looking policies to support their process of trade liberalization.

Secondly, the most disadvantaged regions risk being worse off by the globalization of competition. Hence, we need to improve the governance of the globalization process, establishing a forward looking approach and macroeconomic policies able to limit risk exposure and enhancing the response capabilities of their populations.

\section{References}

[1] Timmer, P., How well do the poor connect to the growth process? CAER Discussion Paper, 17, 1997.

[2] Delgado, C.L., Hopkins, J., \& Kelly, V., Agricultural growth linkages in Sub-Saharan Africa, IFPRI Research Report, 107, 1998.

[3] Edwards, S., Openness, trade liberalisation and growth in developing countries, Journal of Economic Literature, XXXI, pp.1358-1393, 1993.

[4] Frankel A.J., \& Romer, D., Does trade cause growth? The American Economic Review, 89, pp. 379-399, 1999.

[5] Dollar, D. \& Kraay, A., Trade, growth and poverty, World Bank Policy Research Working Paper, 2615, 2001.

[6] Krueger, A.O., Asian trade and growth lessons, American Economic Review, 80, pp. 108-112, 1990. 
[7] Ades, A. \& Di Tella, R., National champions and corruption: some unpleasant interventionist arithmetic, Economic Journal, 107, pp. 10231042, 1997.

[8] Ades, A. \& Di Tella, R., Rents, Competition and Corruption, American Economic Review, 89, pp.982-993, 1999.

[9] Lall, S. \& Pietrobelli, C., Failing to Compete: Technology Development \& Technology Systems in Africa, Edward Elgar: Cheltenham, UK and Lyme, US, 2002.

[10] Alwang, J., Siegel, P.B. \& Jorgensen, S.L., Vulnerability: a view from different disciplines, World Bank Social Protection Discussion Paper Series, 0115, 2001.

[11] Heitzmann, K., Canagarajah, R.S. \& Siegel, P.B., The source of vulnerability: a rationale and guideline for the assessment of risks and risk responses, Prepared for the World Bank Social Protection Discussion Paper Series, 2001.

[12] Ligon, E. \& Schechter, L., Evaluating different approaches to estimating vulnerability, World Bank Social Protection Discussion Paper Series, 0410, 2004.

[13] Holzmann, R. \& Jorgensen, S., Social risk management: a new conceptual framework for social protection and beyond, World Bank Social Protection Discussion Paper, 0006, 2000.

[14] Holzmann, R., Toward an operational and policy-relevant definition of vulnerability, Prepared for the World Bank Social Protection Discussion Paper, 2001.

[15] Dollar, D. \& Kraay, A., Growth is good for the poor, World Bank Policy Research Working Paper, 2587, 2000.

[16] Montalbano, P., Federici, A., Triulzi, U. \& Pietrobelli, C., Trade openness and vulnerability in Central and Eastern Europe (Chapter 9). The impact of globalization on the world's poor - Transmission mechanisms, ed. M. Nissanke and E. Thorbecke, Palgrave Macmillan: Houndmills, Basingstoke and New York, pp. 204-234, 2007.

[17] Ligon, E. \& Schechter, L., Measuring vulnerability, Economic Journal, 113, 95-102, 2003.

[18] Amin, S., Rai, A.S. \& Topa, G., Does microcredit reach the poor and vulnerable? Evidence from northern Bangladesh, Center for International Development at Harvard University Working Paper, 28, 1999.

[19] Glewwe, P. \& Hall, G., Are some groups more vulnerable to macroeconomic shocks than others? Hypothesis tests based on panel data from Peru, Journal of Development Economics, 56(1), pp. 181-206, 1998.

[20] Wolf, H., Accounting for consumption volatility differences, IMF Staff Papers, 51, Special Issue, 2004.

[21] World Bank, Managing Volatility and crises: a practitioner's guide, PREM Economic Policy, Managing Volatility Thematic Group. 